\title{
EL REFUGIO DEL PRI DURANTE LA ALTERNANCIA PANISTA
}

Rogelio HernÁndez Rodríguez

El regreso del pri a la Presidencia de la República en 2012, después de haber sido derrotado en dos ocasiones consecutivas y, más aún, de haber sido desplazado al tercer lugar nacional en 2006, con un porcentaje de apenas $22.3 \%$ de los votos, ha despertado múltiples interrogantes. Más allá de las consecuencias que pueda tener su desempeño en el gobierno de la República, de los cuestionamientos acerca de las condiciones de la democracia mexicana que lo hicieron posible y de la actuación de las dos administraciones del PAN, una pregunta que a muchos observadores inquieta es cómo fue posible que ese partido viejo, desprestigiado, asociado al largo periodo del autoritarismo y, más todavía, que electoralmente parecía tener cada vez menos preferencias, lograra doce años después de su salida de Los Pinos vencer al PAN, dos veces victorioso, y al PRD, permanente opositor, con liderazgos populares y creciente ascenso electoral.

Varias son las respuestas y los factores que lo permitieron, en especial todos aquellos que condicionan el funcionamiento de la democracia mexicana, pero los más importantes dependen del mismo funcionamiento del PRI que le permitió sobrevivir después del año 2000. El PRI no sólo es el partido con mayor penetración organizativa del país, gracias a su historia y tradición política, sino el que mejor se ha asentado en los estados y regiones. La histórica derrota del año 2000 lo expulsó de la Presidencia y, como se verá adelante, destruyó su real liderazgo y con ello su coordinación nacional, pero no lo eliminó de la política, en especial en los estados, donde conservó su presencia, aprendió a competir y a formar nuevas generaciones de políticos. 
La oposición al PRI, por más diferencias ideológicas y políticas que tuviera entre sí, coincidió en una premisa no siempre explícita pero determinante en sus orientaciones, que se definía por la idea de que el partido debía su existencia y presencia electoral a los apoyos indebidos que recibía del gobierno federal y, en un sentido más amplio, del sistema en su conjunto. Bajo esa premisa, el PRI se beneficiaba siempre no sólo de un sistema electoral creado para obstaculizar a la oposición sino de las mismas instituciones políticas que le proporcionaban recursos ilegítimos. De acuerdo con esa propuesta, si el PRI perdía los apoyos iba a perder naturalmente el poder, lo que crearía todas las condiciones para que en el corto plazo desapareciera. Como puede fácilmente advertirse, esa idea no aceptaba que el viejo partido tuviera una estructura funcional, ni militancia ni menos aún real presencia electoral. Como ha sido más que evidente, esa premisa ha sido reiteradamente confrontada por la realidad, pues las frecuentes reformas electorales fueron eliminando todas las ventajas con las que contaba el PRI, y si bien al final permitió su derrota presidencial, de ninguna forma llevaron a su desaparición.

El PRI ha sobrevivido a las adecuaciones políticas, a las reformas electorales y tras años de derrotas nacionales ha logrado construir un liderazgo y, desde luego, aprovechar las oportunidades que los gobiernos de la alternancia le han ofrecido. Sin embargo, el PRI lo ha logrado debido a que cuenta con una historia previa y a que después de las derrotas presidenciales regresó a sus fuentes tradicionales de apoyo, la política local y estatal. Fue en los estados y la política local donde se refugió y logró construir sus nuevos liderazgos. Para entender la historia particular de ese partido durante los años del panismo victorioso, deben tenerse en cuenta los cambios estructurales que tuvieron lugar antes del año 2000 en cuanto a la descentralización del poder, que fue lenta pero consistentemente fortaleciendo la política local. Ese proceso, que como se verá fue obligado por las circunstancias económicas y políticas de las últimas dos décadas del siglo pasado, benefició a todos los gobiernos y mandatarios locales, con independencia de los partidos de origen, pero fue aprovechado en especial por los priistas que gracias a su largo dominio los emplearon para 
conservar las estructuras estatales del PRI y adecuarlas para la competencia política.

El dominio que el PRI ejerció durante la mayor parte del siglo veinte llevó a considerarlo como una organización homogénea, vertical y sobre todo disciplinada, que era dirigida por una autoridad central. La imagen fue equivocada porque aunque el PRI siempre contó con una estructura nacional, no era conducida por una sola dirección sino por autoridades estatales, que eran coordinadas por la presidencia nacional del partido. Desde luego, esa dirección formal estaba supeditada al jefe del ejecutivo que seleccionaba a los dirigentes y decidía los cambios, pero la operación real del partido dependía siempre de los órganos y autoridades locales. La decisión fue, como era característico de ese partido, esencialmente pragmática porque dada la diversidad económica, social y cultural de las regiones y estados, ni el partido ni el mismo ejecutivo federal podían intervenir con éxito en todos los lugares. La política fue delegada a las autoridades locales que, siguiendo el centralismo federal, recayó en los mandatarios.

El equilibrio fue delicado porque los grupos locales siempre existieron y fueron coordinados por los gobernadores, los que a su vez los empleaban para fortalecer su propia influencia. Solamente el control federal, ejercido política y económicamente, pudo mantener la estabilidad en el partido al evitar los conflictos, mediante las recompensas políticas desde luego, pero también con sanciones claras que forzaban la disciplina. La tensión fue histórica y sólo pudo manejarse con éxito gracias al poder indiscutible del presidente la República, quien, en los hechos, fue siempre el líder real del partido.

En el año 2000, cuando el proceso de cambio político puso al PRI fuera de la Presidencia, el partido se sumió en una seria crisis organizativa porque no sólo sufrió la derrota electoral y la pérdida del poder nacional, sino la desaparición de su liderazgo. La pérdida fue decisiva porque desde su más remota versión, el partido nunca tuvo una dirección propia y por el contrario fue ejercida por los presidentes en turno. No había ninguna experiencia en la que el presidente formal condujera realmente el destino de la organización. No sólo abundan las evidencias de cómo los presidentes de 
la República impusieron a los dirigentes del partido, sino también de cómo los removieron cuando no coincidían con los proyectos presidenciales o intentaban hacer realidad su independencia, como fue el caso, ejemplar en más de un sentido, de Carlos A. Madrazo en 1965. En 2000, el PRI de pronto se quedó sin una autoridad reconocida, con verdadera influencia que fuera capaz tanto de darle rumbo al partido como, en especial, de equilibrar los variados intereses locales que, en contraste, sí conservaron el poder y el control de las estructuras del partido en los estados. Esta circunstancia vino a determinar el comportamiento del PRI durante los doce años de alternancia panista, y fue la causa principal de que el partido pudiese sobrevivir política y electoralmente, pero fuera incapaz de recuperar la Presidencia en el corto plazo. El proceso interno, sin embargo, estuvo condicionado por una nueva circunstancia federal que se remonta a diversos cambios efectuados a fines del siglo pasado.

\section{LOS CAMBIOS FEDERALES}

Hacia la década de 1980, cuando México enfrentó una severa crisis económica, la entonces élite gobernante, formada en la disciplina financiera, promovió cambios administrativos y económicos que trasladaron responsabilidades y recursos hacia los gobiernos estatales para aliviar las presiones del federal, agobiado por el creciente gasto y la necesidad de controlar el déficit público. ${ }^{1}$ La medida fue presentada también como una obligada rectificación de las consideradas entonces excesivas responsabilidades del Estado, que, en su afán por aliviar problemas sociales y presiones políticas, se hizo cargo de tareas que no le eran propias y aumentaban el gasto público. Como fue frecuente en aquellos años, el creciente déficit público fue responsabilizado de la inflación, la deuda, las recesiones y, en general, de la severa crisis que afectó prácticamente a todos los países latinoamericanos. ${ }^{2}$ En México el discurso fue

${ }^{1}$ Pedro Aspe, El camino mexicano de la transformación económica, México, FCE, 1993.

${ }^{2}$ Philipe Oxhorn y Pamela K. Starr (eds.), Markets and Democracy in Latin 
efectivo porque el Estado no sólo asumió un fuerte y creciente gasto social sino que históricamente concentró las actividades financieras, fiscales y la obra pública en el país. En medio de la crisis, el gobierno promovió una profunda descentralización de tareas y recursos que en menos de una década canceló actividades y organismos federales, y trasladó responsabilidades a los gobiernos de los estados. Fue así que los municipios ampliaron su autoridad para recaudar y administrar recursos y los gobiernos estatales asumieron el manejo de la educación y la salud, entre otras tareas, antes federales. A principios de los años noventa se promovió la última modificación del esquema de recaudación fiscal y distribución de los recursos federales a los estados, con lo cual se dotó no sólo de recursos económicos a los mandatarios, sino de autonomía para administrarlos y desarrollar obra pública por su cuenta. ${ }^{3}$

Aunque la recaudación fiscal sigue siendo centralizada por el gobierno federal, existe un esquema objetivo, basado en indicadores económicos, sociales y contables, que determinan los montos de financiamiento a los estados y que está encaminado a evitar, o al menos contener, los desequilibrios económicos de los estados. A ello debe añadirse que el presupuesto que se destina a los estados cuenta con mínimos procedimientos de vigilancia y evaluación que, además, en su mayoría están en manos de los congresos locales, de tal manera que los mandatarios gozan ahora de una extraordinaria independencia económica y, desde luego, política. ${ }^{4}$ Este punto es determinante porque desde ese momento los gobernadores pueden planear y desarrollar actividades económicas y sociales que antes dependían del presidente y sus secretarios de Estado, y que ahora, al realizarlas a su arbitrio, pueden redituarles

America, Boulder, Lynne Rienner Publishers, 1999; también: Rudiger Dornbusch y Sebastian Edwards, The Macroeconomics of Populism in Latin America, Chicago, University of Chicago Press, 1991.

${ }^{3}$ Victoria Rodríguez, La descentralización en México, México, FCE, 1999; y con Peter M. Ward, New Federalism and State Government in Mexico: Bringing the States Back-In, US-Mexico Policy Studies Monograph Series, núm. 10, LBJ School of Public Affairs, The University of Texas at Austin, 1999.

${ }^{4}$ Rogelio Hernández Rodríguez, El centro dividido. La nueva autonomía de los gobernadores, México, El Colegio de México, 2008. 
significativas ganancias políticas y electorales. Los recursos económicos se han convertido en una fuente de independencia, en principio estatal, pero sobre todo para los grupos y liderazgos políticos de cada entidad.

La autonomía económica se fortaleció con otro fenómeno, por completo independiente a la descentralización, pero coincidente en el tiempo, como fue la creciente competencia política electoral. Por razones entendibles, la democratización del país se ha identificado con la alternancia en la Presidencia, ocurrida en 2000, pero en realidad esa cualidad democrática se presentó muchos años antes en las entidades del país. En los mismos años ochenta en que tuvo lugar la descentralización administrativa y económica, también se produjo la más intensa competencia partidaria que condujo a frecuentes reformas electorales, triunfos de partidos opositores al PRI y a una mayor participación ciudadana en las elecciones. ${ }^{5} \mathrm{Al}$ menos dos décadas antes del año 2000, la oposición, tanto de derecha como de izquierda, consiguió triunfos en municipios, congresos locales, en 1989 la primera gubernatura (que hasta ahora continúa en manos del PAN) y en 1997 la mayoría en el congreso federal, al cual, desde entonces, ningún partido ha logrado dominar hasta el momento. Hacia el año 2000, cuando el PAN consiguió la Presidencia de la República, la alternancia era un hecho comprobable en la política local, en las instituciones legislativas y en las gubernaturas, lo que indicaba tanto el avance de la democracia como el resurgimiento de nuevos actores políticos, presentes en el sistema pero históricamente marginados por el autoritarismo.

La competencia en los gobiernos de los estados tuvo dos consecuencias directas. La primera fue la aparición, del todo desconocida en la política nacional, de gobernadores procedentes de otros partidos; la segunda fue que los surgidos del PRI asumieran un mayor liderazgo tanto en la estructura del partido en sus estados como de las instituciones estatales, con el objetivo de enfrentar

${ }^{5}$ Mauricio Merino, La transición votada, México, FCE, 2003; también: Pedro Becerra et al., La mecánica del cambio político en México: elecciones, partidos y reformas, México, Cal y Arena, 2000. 
con criterios locales a la oposición cada vez más fortalecida. En ambos casos, los mandatarios tuvieron una independencia económica y financiera que les permitió romper con la tradicional subordinación al gobierno federal, al presidente y a los secretarios de Estado. $^{6}$

En esos años el PRI también vivió un lento proceso de adaptación política. En 1982 llegó al poder una nueva élite priista, convencionalmente llamada tecnocrática, debido no a su origen en el sector público que, en rigor, era compartido con las generaciones anteriores, sino a su formación particular en las áreas financieras del gobierno federal. ${ }^{7}$ Para esta nueva generación era necesario corregir la política económica, primero, para superar la crisis y luego para incorporar al país a las condiciones de la economía internacional, lo que suponía también asegurarse el control de la política. La rectificación económica de las últimas dos décadas del siglo y la democratización del país descrita páginas antes tuvieron lugar durante los gobiernos encabezados por la tecnocracia priista de Miguel de la Madrid, Carlos Salinas de Gortari y Ernesto Zedillo (1982-2000). Los políticos llamados desde entonces tradicionales fueron relegados de los puestos gubernamentales y, en general, sobrevivieron en los gobiernos estatales y el partido. Las diferencias y desencuentros entre estas dos élites priistas dieron como resultado cambios internos en el PRI que favorecieron las representaciones estatales ante la pérdida del liderazgo presidencial y fortalecieron a los mandatarios que, como era tradicional en el priismo, mantuvieron el contacto y la autoridad con las militancias de los estados.

Un dato revelador de los cambios ocurridos en estos años y que se manifestaba en la aparición de nuevos liderazgos es la aguda crisis que tuvo lugar en 1999 cuando dos gobernadores en funciones (Roberto Madrazo de Tabasco y Manuel Bartlett de Puebla) aspiraron a la candidatura presidencial y enfrentaron, en novedosas condiciones de competencia interna, basadas en elecciones

${ }^{6}$ Peter M. Ward y Victoria E. Rodríguez, "New Federalism, Intra-governmental Relations and Co-governance in Mexico", Journal of Latin American Studies, núm. 3, octubre de 1999 .

${ }^{7}$ Isabelle Rousseau, México: ¿una revolución silenciosa? Élites gubernamentales y proyecto de modernización (1970-1995), México, El Colegio de México, 2000. 
primarias, al entonces secretario de Gobernación y candidato del presidente Zedillo, Francisco Labastida. Aunque el secretario ganó la candidatura, no logró la unificación del partido, lo que le restó posibilidades ante el candidato popular de Acción Nacional, Vicente Fox, quien, como Madrazo y Bartlett, era gobernador en funciones. No hay duda de que no sólo la política se había descentralizado, sino que había colocado en una posición muy ventajosa a los mandatarios priistas, pero también de los que provenían del PAN y del PRD, de tal manera que se habían convertido en líderes relevantes en lugar de los secretarios de Estado.

\section{EL REFUGIO DEL PRI}

La intensa competencia política que tuvo lugar en las últimas décadas del siglo veinte fue estimulada por la larga serie de reformas electorales que si bien buscaban mejorar la competencia partidaria, también se dirigían a terminar con los apoyos indebidos que recibía el priismo. Las reformas, que llegarían a su mayor profundidad en cuanto al diseño institucional, con la autonomía del IFE en 1996, sin duda abrieron el camino a la alternancia al crear un auténtico y creíble árbitro electoral, que dio certidumbre tanto a partidos como a los ciudadanos. El PRI perdió las elecciones presidenciales en 2000 y de nuevo en 2006, pero contra todos los pronósticos, no desapareció ni dejó de ser un actor determinante en la política nacional. ${ }^{8}$

El PRI, como todo partido autoritario, ${ }^{9}$ no nació para competir en elecciones, por más que puntualmente participara en ellas. No

8 Alberto Aziz, "La construcción de la democracia electoral", en Ilán Bizberg et al. (comps.), Una historia contemporánea de México, t. 1, México, Océano, 2003.

${ }^{9}$ En los sistemas autoritarios, como lo explicara Linz en su clásico ensayo, los partidos dominantes fueron creados para conservar el poder, no para obtenerlo, como en las dictaduras, o para competir, como en las democracias. Juan J. Linz, “An Authoritarian Regime: Spain”, en Eric Allardt y Stein Rokkan (eds.), Mass Politics, Nueva York, The Free Press, 1970. Para el caso del PRI sigue siendo revelador el trabajo de Samuel P. Huntington, "Social and Institutional Dynamics of One-Party Systems", en Samuel P. Huntington y Clement H. Moore, Authoritarian Politics in Modern Society: The Dynamics of Established One-Party Systems, Nueva York, Basic Books, Inc. Publisher, 1970. 
obstante, su larga vida y las obligadas reformas que lenta pero sostenidamente permitieron la competencia lo forzaron a adaptarse a las nuevas circunstancias. Esta capacidad de adaptación siempre fue subestimada por sus adversarios, y en ella basaron la expectativa de que el PRI irremediablemente sería derrotado. Y es verdad que el comportamiento electoral muestra una creciente disminución de votos a su favor, conforme el sistema electoral mejoraba, pero lejos de desaparecer el PRI consolidó su mercado electoral y, sobre todo, mejoró sus habilidades como maquinaria partidaria.

A pesar de los descalabros, el PRI mantuvo su presencia en los estados. Sin el liderazgo presidencial que lo mantenía unido como partido nacional, al convertirse en árbitro y autoridad final, el partido dispersó su poder en liderazgos institucionales (gubernaturas y bancadas legislativas) y en grupos diversos. Como era tradicional en el PRI, los liderazgos más fuertes fueron los locales, encabezados por los mandatarios que conservaron el poder después de 2000. Sin árbitro nacional, los gobernadores no asumieron la dirección del partido, pero sí la conducción de las maquinarias electorales locales.

A partir de la derrota presidencial, fue claro para los priistas que su sobrevivencia como partido dependía de la construcción inmediata de una autoridad central. La tarea determinó las acciones de los dirigentes y los grupos. Apenas concluido el proceso electoral, el priismo se concentró en preparar una nueva asamblea que diera como resultado un nuevo dirigente, fuerte y reconocido, que marcara el rumbo de la organización. En la preparación fueron evidentes dos proyectos de partido: el más fuerte por el número de sus participantes y poder real fue el de los gobernadores, que pretendía elegir un presidente sometido a su voluntad, lo que supondría la construcción de frecuentes acuerdos entre líderes que no siempre compartían el mismo interés. El otro proyecto lo encabezaba Roberto Madrazo, con pocas simpatías entre los mandatarios pero con gran aceptación de los militantes, que proponía un liderazgo institucional, independiente de grupos y gobernadores. ${ }^{10}$ Aunque la confrontación de 2000 que desembocó

${ }^{10} \mathrm{El}$ análisis puntual de este episodio así como de la presidencia de Madrazo se encuentra en Rogelio Hernández Rodríguez, "Una competencia sin reglas: la 
en la XVIII Asamblea Nacional se desarrolló a la sombra de la derrota presidencial, en realidad estuvo condicionada por las batallas previas que se originaron en los preparativos para seleccionar al candidato a la Presidencia, en las que los mandatarios jugaron un papel central ante la ya muy debilitada influencia del entonces mandatario Ernesto Zedillo. Hacia 1999 el presidente vio profundamente limitadas sus atribuciones después de que la XVII Asamblea Nacional impusiera sus conocidas condiciones de militancia comprobada y experiencia en puestos de elección popular.

Con esos cambios, Zedillo no pudo imponer a su candidato y se vio obligado a buscar el apoyo de los gobernadores, quienes en la asamblea XVII habían logrado aumentar su presencia en la dirección colegiada del PRI. Fueron ellos y la Secretaría de Gobernación los que diseñaron el esquema de elecciones internas en las que el ganador sería el que obtuviera la mayoría de distritos y no el mayor número de votos. Era un esquema muy conocido en su funcionamiento, en especial por el potencial riesgo de conflicto que puede originarse entre los resultados, pero que fue adoptado deliberadamente porque dejaba el control de las casillas en los distritos, sujetos al mando de los dirigentes estatales y, por ende, en los gobernadores. El resultado de esa votación fue el esperado por los organizadores, pues el triunfo fue arrollador para el candidato Francisco Labastida, a pesar de que en la elección participaron dos gobernadores con fuertes apoyos de la militancia, como fueron Manuel Bartlett y principalmente Roberto Madrazo. ${ }^{11}$

candidatura presidencial de Roberto Madrazo”, Política y gobierno, CIDE, 2009. Sobre la elección de Madrazo y las condiciones reglamentarias de las asambleas, véanse los ensayos de Guadalupe Pacheco, "La redefinición de las reglas internas de poder en el PRI, 1988-2001. De la XIV a la XVIII Asamblea Nacional”, Argumentos, núm. 43, diciembre de 2002; y, “¿Hacia la cuarta etapa del partido de la Revolución? La elección interna de dirigentes del PRI en febrero de 2002”, Foro Internacional, núm. 184, abril-junio de 2006.

${ }^{11}$ Francisco Labastida obtuvo 272 de los 300 distritos, mientras que Madrazo obtuvo 21 y Bartlett siete. Las cifras fueron de $54.8 \%$ de la votación para Labastida, 28.4\% para Madrazo y 5.9\% para Bartlett, de un total de 9739251 votos. Voz y Voto, núm. 82, diciembre de 1999 . 
$\mathrm{Al}$ presentarse la elección del dirigente nacional del PRI después de los comicios de 2000, en los que Labastida fue derrotado, Madrazo cobró gran importancia, pese a que no contaba con el apoyo de los mandatarios, quienes se habían agrupado en torno del candidato derrotado. Madrazo naturalmente se convirtió en candidato a la dirigencia, frente a Beatriz Paredes, a quien la mayoría de gobernadores apoyaba. Conscientes de su poder, del que ya habían dado muestras en 1999, los gobernadores volvieron a proponer las elecciones internas por mayoría de distritos, pero Madrazo se opuso y logró que en la XVIII Asamblea Nacional los delegados aprobaron la mayoría simple de votos, lo que indicaba que había una fuerte corriente de apoyo a Madrazo, en buena medida propiciada por el fracaso electoral de Labastida. Sin embargo, la misma asamblea demostró que el proyecto de Madrazo no contaría con suficientes apoyos institucionales porque los delegados aprobaron aumentar la influencia de los gobernadores al permitir que todos los mandatarios priistas tuvieran presencia en el Consejo Político Nacional. El comportamiento de los delegados revelaba, por un lado, la presencia de una militancia fuerte que podía oponerse a los grupos locales y que más tarde sería esencial en la administración de Madrazo, pero, por otro, que el poder de los liderazgos locales podría ejercer fuertes vetos al próximo dirigente. Este precario equilibrio marcó el futuro del priismo en los años siguientes.

Madrazo ganaría las elecciones para la presidencia del partido con el voto abierto de los militantes y el apoyo sindical del SNTE, gracias a que su dirigente, Elba Esther Gordillo, acompañó a Madrazo como secretaria general. Ganó la dirigencia nacional, pero su proyecto de construir una presidencia independiente no conseguiría hacerlo realidad porque no podría superar el poder de los mandatarios. Con todo, Madrazo consiguió fortalecerse mediante negociaciones frecuentes que estuvieron encaminadas a recuperar la presencia electoral del PRI en las elecciones locales y federales de 2003. De acuerdo con los resultados, el periodo de Madrazo fue notablemente efectivo porque logró que el PRI se afirmara en las elecciones de medio término como el partido con mayor fuerza electoral en el Congreso. Como se ve en el cuadro 1, el PRI logró aumentar su presencia en la Cámara de Diputados en 2003, tras 
los frecuentes desencuentros del presidente Vicente Fox con el Congreso y la evidente parálisis gubernamental que se provocó. Pero quizá donde sea más reveladora la recuperación del priismo es en los triunfos que consiguió en las gubernaturas, pues entre 2000 y 2006 de las 28 gubernaturas que se disputaron el PRI mantuvo 17 , algunas ganadas con anterioridad por la oposición. ${ }^{12}$

\section{Cuadro 1}

Cámara de Diputados, 1994-2015 Porcentajes

\begin{tabular}{llllll}
\hline Legislatura & $P R I$ & $P A N$ & $P R D$ & Otros & Total \\
\hline $1994-1997$ & 60.0 & 23.8 & 14.2 & 2.0 & 500 \\
$1997-2000$ & 47.8 & 24.4 & 25.0 & 2.8 & 500 \\
$2000-2003$ & 42.2 & 41.4 & 10.2 & 6.2 & 500 \\
$2003-2006$ & 44.8 & 30.2 & 19.4 & 5.6 & 500 \\
$2006-2009$ & 21.2 & 41.4 & 25.4 & 13.0 & 500 \\
$2009-2012$ & 47.4 & 28.6 & 14.2 & 9.8 & 500 \\
$2012-2015$ & 42.6 & 22.8 & 20.2 & 14.4 & 500 \\
\hline
\end{tabular}

Fuente: Cámara de Diputados. México.

La presidencia de Madrazo fue efectiva en la construcción de acuerdos coyunturales, todos encaminados a asegurar los intereses locales, de ahí que tanto las elecciones para gobernadores como las de diputados federales hayan rendido buenos resultados al priismo. Al final, estaban en juego la influencia de los grupos y liderazgos locales, pero no fue lo mismo al momento de competir por la Presidencia de la República en 2006, cuando los dos grandes grupos volvieron a enfrentarse, esta vez con la esperanza de recuperar el poder nacional. Madrazo, contra la tradición priista, empleó los recursos y la influencia de la dirección del partido para construir su candidatura, pero contra los deseos de los mandatarios que, de nuevo, se organizaron en su contra. Si bien Madrazo

${ }^{12}$ Las elecciones para las gubernaturas de Chiapas, Guanajuato y Morelos, así como la jefatura de gobierno del Distrito Federal, coinciden con las presidenciales. Las cuatro fueron ganadas por el PAN y el PRD. 
obtuvo la candidatura, lo hizo después de una desgastante confrontación interna en la que los gobernadores nunca ocultaron su desacuerdo. En 2005 Madrazo se convirtió en candidato luego de que su principal competidor, Arturo Montiel, gobernador del influyente Estado de México, abandonara la contienda en medio de acusaciones de corrupción, pero con el apoyo de la mayoría de los mandatarios. Madrazo ganó sobre la base de la estructura del partido, al designar dirigentes y delegados, aprovechar las visitas oficiales a los estados para promover su candidatura, pero no logró subordinar los poderes internos que, en la práctica, operan la maquinaria del partido.

Esto explica el aparentemente contradictorio desempeño electoral del PRI. Como se observa en los cuadros 1 y 2, el partido ha conservado sin lugar a dudas la mayoría de los votos ciudadanos desde 1994, a pesar de los descalabros de 2000 y sobre todo de 2006. Se ha mantenido como la principal fuerza del Congreso, donde ha conservado la primera mayoría con la única excepción de 2006, y ha mantenido el mayor número de gobiernos estatales. Esta indudable presencia del PRI revela que es un partido con gran influencia local y regional, pues tanto los diputados federales como evidentemente las gubernaturas expresan intereses locales, pero no pudo conseguir la Presidencia de la República hasta doce años después. Dicho en otras palabras, la presencia nacional del PRI, que depende de sus organismos estatales, solamente puede coordinarse para un propósito nacional si cuenta con un liderazgo con autoridad reconocida por los diferentes grupos. Madrazo fue capaz de conducir al partido siempre que se tratara de comicios locales, pero no fue el dirigente que los variados liderazgos reconocieran para ser su candidato a la Presidencia.

Esta circunstancia queda más clara si se atiende a la manera en que se ha desarrollado la competencia local en México, antes y después de las elecciones de 2000. Como se observa en el cuadro 2, el PRI ha conservado la mayoría de las gubernaturas en el país, incluso en 2006, cuando la caída en las presidenciales afectó su desempeño local. Aunque los otros dos partidos han aumentado su presencia federal, en ningún momento han superado la mayoría priista, ni siquiera en conjunto. El número de gubernaturas es tan 
sólo un indicador de la verdadera presencia del partido en las elecciones, pues ha conservado intactas varias (destacadamente en los estados de México e Hidalgo, que, como se verá en el apartado siguiente, tienen especial relevancia para la conformación de la nueva élite), pero también ha recuperado otras que en su momento parecían bastiones del PAN y del PRD (cuadro 3). Un dato adicional que se desprende del cuadro 3 es que en todas las entidades el PRI es el más fuerte adversario, lo que ha convertido la competencia en enfrentamientos de dos partidos, en donde el PRI cambia de adversario fuerte, ya sea el PAN o el PRD, pero rara vez compromete a los dos opositores. Y también en raras excepciones la competencia ha involucrado únicamente al PAN frente al PRD.

Cuadro 2

Gubernaturas por partido político, 1988-2012

\begin{tabular}{lrrrrr}
\hline Partido & $1988^{*}$ & 1994 & 2000 & 2006 & 2010 \\
\hline PRI & 30 & 28 & 20 & 17 & 20 \\
PAN & 1 & 3 & 9 & 9 & 6 \\
PRD & 0 & 0 & 3 & 6 & 4 \\
Otros & 0 & 0 & 0 & 0 & 2 \\
\hline
\end{tabular}

* Hasta 1997 el Distrito Federal no fue una entidad federativa sino un departamento administrativo, dependiente del ejecutivo federal. En ese año se establecieron elecciones para elegir jefe de Gobierno.

Fuente: Institutos Electorales Estatales, resultados electorales.

Solamente cuatro entidades (Baja California Sur, Chiapas, Morelos y Tlaxcala) han experimentado competencias en las que los tres grandes partidos han tenido oportunidades similares. En las 22 entidades en que se ha presentado la alternancia en sus gobiernos, siempre el PRI ha tenido un papel relevante. Los datos muestran, por un lado, que la alternancia es un hecho bien asentado en el país, toda vez que de las 32 entidades solamente diez no han pasado por esa prueba, pero el resto ha tenido entre uno y tres cambios de partido (cuadro 4). Por supuesto que en los diez estados sin 
Cuadro 3

Alternancia política en los estados, 1988-2012

\begin{tabular}{|c|c|c|c|c|c|c|}
\hline Entidad & 1988 & 1994 & 2000 & 2006 & 2012 & Cambios \\
\hline Aguascalientes & PRI & PRI & PAN & PAN & PRI & 2 \\
\hline Baja California & PAN & PAN & PAN & PAN & PAN & 1 \\
\hline Baja California Sur* & PRI & PRI & PRD & PRD & PAN & 2 \\
\hline Campeche & PRI & PRI & PRI & PRI & PRI & 0 \\
\hline Chiapas* & PRI & PRI & PAN & PRD & PV-PRI & 3 \\
\hline Chihuahua & PRI & PAN & PRI & PRI & PRI & 2 \\
\hline Coahuila & PRI & PRI & PRI & PRI & PRI & 0 \\
\hline Colima & PRI & PRI & PRI & PRI & PRI & 0 \\
\hline Distrito Federal $^{\mathrm{a}}$ & - & - & PRD & PRD & PRD & 0 \\
\hline Durango & PRI & PRI & PRI & PRI & PRI & 0 \\
\hline Guanajuato & PRI & PAN & PAN & PAN & PAN & 1 \\
\hline Guerrero & PRI & PRI & PRI & PRD & PRD & 1 \\
\hline Hidalgo & PRI & PRI & PRI & PRI & PRI & 0 \\
\hline Jalisco & PRI & PRI & PAN & PAN & PRI & 2 \\
\hline México, Estado de & PRI & PRI & PRI & PRI & PRI & 0 \\
\hline Michoacán & PRI & PRI & PRI & PRD & PRI & 2 \\
\hline Morelos* & PRI & PRI & PAN & PAN & PRD & 2 \\
\hline Nayarit & PRI & PRI & PAN & PRI & PRI & 2 \\
\hline Nuevo León & PRI & PRI & PAN & PRI & PRI & 2 \\
\hline Oaxaca & PRI & PRI & PRI & PRI & Converg. & 1 \\
\hline Puebla & PRI & PRI & PRI & PRI & PAN & 1 \\
\hline Querétaro & PRI & PRI & PAN & PAN & PRI & 2 \\
\hline Quintana Roo & PRI & PRI & PRI & PRI & PRI & 0 \\
\hline San Luis Potosí & PRI & PRI & PRI & PAN & PRI & 2 \\
\hline Sinaloa & PRI & PRI & PRI & PRI & PAN & 1 \\
\hline Sonora & PRI & PRI & PRI & PRI & PAN & 1 \\
\hline Tabasco & PRI & PRI & PRI & PRI & PRD & 1 \\
\hline Tamaulipas & PRI & PRI & PRI & PRI & PRI & 0 \\
\hline Tlaxcala* & PRI & PRI & PRD & PAN & PRI & 3 \\
\hline Veracruz & PRI & PRI & PRI & PRI & PRI & 0 \\
\hline Yucatán & PRI & PRI & PRI & PAN & PRI & 2 \\
\hline Zacatecas & PRI & PRI & PRI & PRD & PRI & 2 \\
\hline
\end{tabular}

${ }^{\text {a Hasta }} 1997$ el Distrito Federal fue un departamento administrativo, dependiente del ejecutivo federal y el regente era nombrado por el presidente de la República. En ese año tuvo lugar la primera elección para elegir al jefe de Gobierno y desde entonces ha gobernado el PRD.

* Estados con alternancia de los tres partidos.

Fuente: Investigación propia con datos electorales de los estados. 
cambios el PRI es dominante, pero no depende necesariamente del partido sino de las condiciones locales; la prueba es que en dos de ellas los partidos ganadores han sido el PAN, que ha gobernado sin interrupciones Baja California desde 1989, y el PRD, que ha ganado con mayorías aplastantes y de manera continua, nada menos que el Distrito Federal. Pero también se comprueba, por otro lado, que en todas las entidades el PRI ha sido un fuerte competidor y que ha aprendido a enfrentar con éxito a sus oponentes. El hecho de que la competencia en los estados sea bilateral y de que en ella siempre esté presente el PRI, demuestra que ese partido es el único con verdadera presencia nacional, con estructura funcional y militancia activa, además, claro está, de contar con preferencias reales entre el electorado.

\begin{tabular}{lc}
\multicolumn{2}{c}{ CuAdro 4} \\
Alternancia política en los estados \\
Número de cambios, & 1988-2012 \\
& \\
\hline Alternancia & Estados \\
\hline Sin alternancia & 10 \\
Una vez & 8 \\
Dos veces & 12 \\
Tres veces & 2 \\
\hline
\end{tabular}

Fuente: cuadro 3.

Lo anterior explica que, pese a las derrotas presidenciales, el PRI sea el partido mayoritario en el Congreso. El cuadro 1 muestra el porcentaje de escaños de los tres principales partidos desde 1994, cuando el PRI perdió definitivamente la mayoría calificada en el Congreso. Como se observa, si bien el PRI mantiene una caída entre la primera y la segunda legislaturas, se estabiliza en cerca de $45 \%$ a partir de entonces. La única ocasión en que el PRI perdió la mayoría simple fue en 2006 como consecuencia de la derrota presidencial. Pero fuera de esa excepción siempre ha sido la primera fuerza política en el legislativo. Éste es un dato aún más importante si se advierte que las variaciones del PAN y el PRD son más pronunciadas 
y revelan cambios radicales entre las elecciones presidenciales y las de medio término, lo que sugiere, en las primeras, el arrastre de los candidatos a la Presidencia, y en las segundas, castigos electorales al desempeño gubernamental. Pero mientras el PAN y el PRD se ven afectados por esos estímulos coyunturales, el PRI mantiene el mismo promedio. Aun en el caso de 2006, el electorado le regresó su apoyo tres años más tarde en un porcentaje superior al de otras legislaturas. Los datos indican que el PRI ya no depende, como se supuso en el pasado, de apoyos indebidos, sino de reales simpatías ciudadanas y de una eficaz maquinaria electoral. Pero acaso lo más importante para el tema de este ensayo es que mantiene una importante presencia en los estados, donde no sólo sobrevivió, sino que aprendió y se habituó a competir. Éste es el punto a subrayar: si bien el PRI se desarrolló en un sistema altamente centralizado, política y económicamente, pudo adaptarse con relativa facilidad a la descentralización y el pluralismo, no sólo aprendiendo a competir sino formando una nueva generación de políticos.

\section{LA NUEVA GENERACIÓN PRIISTA}

La influencia de los gobernadores dentro del PRI se remonta apenas a la última década del siglo pasado. En el sistema tradicional, los mandatarios fueron actores políticos con importantes responsabilidades pero restringidos al ámbito local. Durante todo el dominio priista, fue el gobierno federal el encargado de la obra pública, económica y social, y retuvo los mecanismos que garantizaban el sometimiento de los gobernadores. Sin embargo, el proceso de descentralización económica y administrativa, así como el avance del pluralismo, devolvió a los gobiernos locales su autonomía. El cambio redefinió la política nacional con la aparición de mandatarios de otros partidos, pero también los mismos priistas empezaron a ejercer una influencia hasta entonces desconocida que enfrentó al propio ejecutivo federal. Durante el gobierno de Ernesto Zedillo hubo serias confrontaciones entre la Presidencia de la República y algunos gobernadores que exhibieron, por primera vez en la historia del PRI, no sólo un poder e independencia notable de los 
gobernadores, sino una singular debilidad del ejecutivo federal para someterlos y, de paso, que el presidente de la República ya no tenía el liderazgo sobre la élite priista.

De entre los variados conflictos que Zedillo enfrentó, ${ }^{13}$ destacan los que escenificaron los mandatarios Madrazo, gobernador de Tabasco, que resistió los intentos del presidente por retirarlo del cargo, y Bartlett, gobernador de Puebla, quien logró establecer un procedimiento local para redistribuir el presupuesto federal. Ambos resultaron victoriosos y gracias a ello consiguieron afirmar su autoridad entre la militancia. Con liderazgos estatales fuertes y con reconocimiento entre los priistas, al final del sexenio buscaron la candidatura presidencial en el partido. Su presencia y apoyo fueron tan destacados, que forzaron las elecciones internas de las que resultó triunfador Labastida. Esa primera y abierta confrontación interna demostró que para el PRI era más importante el control de la estructura partidaria que, como había sido en el pasado, la influencia ejercida desde el gabinete presidencial. Después de 2000 este proceso se profundizó y convirtió a los mandatarios en los principales actores en el PRI. De su desempeño formal como jefe de gobierno dependería el apoyo ciudadano, pero de su control político y su visibilidad dependería su influencia en la militancia. En el primer sexenio panista Madrazo logró el control de la estructura nacional del PRI, pero no pudo imponerse a los mandatarios que siguieron manejando a su arbitrio las maquinarias locales. El cambio tuvo lugar en la segunda experiencia panista, cuando un joven político como Enrique Peña Nieto desarrolló una administración eficaz en el Estado de México y aprovechó los recursos a su disposición para promover su imagen en todo el país. Con un notable control sobre la maquinaria local (por lo demás, característico de los mandatarios en esa entidad), Peña Nieto remontó el voto opositor en las elecciones intermedias, con tal éxito que prácticamente desapareció al PAN y al PRD de la representación local, y preparó las condiciones para que fuera elegido su sucesor. Sin abandonar el cargo de gobierno, Peña Nieto pudo

${ }^{13}$ El recuento de estas confrontaciones se encuentra en Rogelio Hernández Rodríguez, El centro..., capítulo vi. 
mantener su influencia entre el priismo e incluso auxiliar a sus compañeros de partido en sus campañas en otras entidades. ${ }^{14}$

El liderazgo del PRI regresó naturalmente a su fuente, los mandatarios, y en especial a aquella que ofrecía los mejores resultados para el partido. Una vez concluido el periodo de Madrazo, con un histórico fracaso electoral, la dirigencia del PRI fue puramente formal. A ella llegaron Mariano Palacios Alcocer (2005-2007) y Beatriz Paredes (2007-2011), quienes, a pesar de su experiencia política, no lograron ejercer verdadera influencia en el partido debido a las circunstancias que las elecciones de 2006 crearon para el presidente Felipe Calderón. La mínima diferencia que le dio la victoria sobre el candidato del PRD se reflejó en una composición inusual en el Congreso y en especial en la Cámara de Diputados (cuadro 1), porque por primera vez los partidos con mayor representación fueron el PAN y el PRD, verdaderos contendientes por la Presidencia, pero debido a la intransigencia de la izquierda, que se negó a colaborar con el ejecutivo y su partido, el PRI cobró una importancia política que no se sustentaba en su posición parlamentaria. En los hechos, los líderes de las bancadas priistas (Beltrones en el Senado y Gamboa Patrón en la segunda legislatura) asumieron la intermediación con el ejecutivo para aprobar algunas iniciativas y los mandatarios la responsabilidad en las elecciones intermedias, de tal manera que los presidentes nacionales del PRI no tuvieron capacidad real para conducir al partido. Esa fue la circunstancia que favoreció a Peña Nieto como líder estatal y le abrió la puerta para imponerse al resto de mandatarios, algunos de los cuales ayudó a hacer sus campañas. La intermediación legislativa del PRI, la debilidad del calderonismo y la fuerte influencia de los mandatarios rindieron frutos al viejo partido, pues en 2009 el PRI ganó 47.4\% de la Cámara de Diputados y fue aumentando su presencia en las gubernaturas hasta alcanzar las veinte en 2012.

Muy pronto Peña Nieto fue construyendo la imagen de un líder capaz dentro del priismo, muy por encima de cualquiera otro

14 Como lo reportaba la prensa local y nacional, durante su sexenio Peña Nieto visitaba los estados donde el PRI tenía elecciones y en más de una ocasión el PRI del Estado de México apoyaba con diversos recursos las campañas locales. 
de sus semejantes, y aprovechó bien los recursos económicos del estado para promoverse en los medios de comunicación. Desde febrero de 2009, cuando aparecieron las primeras encuestas sobre preferencias electorales sin que los partidos tuvieran candidatos formales todavía, Peña Nieto ya destacaba como el más reconocido priista. De acuerdo con las encuestas de esa fecha, Peña Nieto no sólo se sobreponía a sus competidores internos, sino que obtenía las preferencias ciudadanas más altas en cualquier combinación que presentaran los partidos de oposición: $47 \%$ en promedio, frente al $17 \%$ del PAN y el $15 \%$ del PRD. ${ }^{15}$ Conforme se acercaba la postulación del candidato, en el PRI no había dudas de que Peña Nieto era el más destacado político y el que ofrecía las mayores posibilidades de competencia. Con esa ventajosa posición, que en el pasado inmediato ningún priista había logrado con los liderazgos institucionales (Madrazo, presidente del PRI, Montiel, gobernador del Estado de México, Enrique Jackson y Manlio Fabio Beltrones, líderes de las bancadas en el Senado), Peña Nieto consiguió sin ningún obstáculo la candidatura del PRI. Su ascendencia entre la élite priista le permitió unificar a líderes y grupos y, sobre todo, ordenar bajo su mando la maquinaria electoral.

\section{EL PRESIDENTE Y SU GABINETE}

El perfil político de Peña Nieto y de su gabinete es en varios aspectos notablemente diferente al que mostraron las generaciones priistas anteriores. No sólo refleja la obligada ruptura que sufrió la élite al permanecer fuera del poder durante doce años, sino las condiciones que le permitieron sobrevivir nacionalmente. En rigor, esta nueva generación muestra con claridad el lugar donde se refugiaron los priistas de la alternancia: los estados, que fueron las arenas de competencia, de preparación y de negociación.

Peña Nieto es el primer presidente priista que no cuenta en su trayectoria con ningún puesto en el gobierno federal, y el primero, incluidos priistas y panistas, que tampoco ha tenido puestos de

${ }^{15}$ Carta Parametría, Recopilación de encuestas nacionales, abril-mayo de 2011. 
elección federal, como diputado o senador. La carrera del actual presidente ha sido exclusivamente estatal, en puestos de elección (diputado local y gobernador) y, en especial, en el gobierno del estado (subsecretario de Gobierno y secretario de Administración), sin contacto alguno con las instituciones que tradicionalmente habían formado a los políticos priistas. Además de esta característica, debe añadirse que, al igual que Fox en 2000, Peña Nieto también deja inmediatamente una gubernatura. No es el primer caso, desde luego, ni siquiera en la tradición priista, pues ya habían sido mandatarios locales algunos presidentes, pero cobra importancia ahora porque ese antecedente no se había vuelto a presentar desde 1952, cuando el presidente Ruiz Cortines había sido poco antes gobernador de Veracruz. Desde el ascenso de López Mateos en 1958, los jefes del ejecutivo fueron perdiendo sus carreras electorales y de manera destacada, las gubernaturas.

Eso demuestra, primero, la ascendencia que los gobernadores han adquirido en las últimas décadas, y, segundo, que los priistas, aun sin el control del gobierno federal, pueden reproducir a sus militantes. La entidad de la que procede el actual mandatario es, en sí misma, relevante en la política nacional y en la élite priista. El Estado de México se ha caracterizado por haber formado una de las élites locales más profesionales, más disciplinadas y competitivas del priismo. ${ }^{16}$ El Estado de México es una de las diez entidades que no ha experimentado aún la alternancia en la gubernatura pero que, en contraste, ha tenido una activa competencia local en la que los dos partidos de oposición más fuertes han conseguido dominar numerosos municipios, en ocasiones el congreso local, e incluso gobernar la capital del estado, Toluca. Si la homogeneidad de la élite local no se ha minado con el tiempo, la intensa competencia la ha aleccionado para hacer más eficiente

16 Tan significativa ha sido su homogeneidad, que ha dado origen a uno de los mitos más enraizados en la política mexicana, como es el del grupo Atlacomulco, único, dominante y con líderes sucesivos. Demostrar lo insostenible de la idea rebasa con mucho los propósitos de este ensayo, pero el lector interesado puede consultar: Rogelio Hernández Rodríguez, Amistades, compromisos y lealtades. Lideres y grupos políticos en el Estado de México, 1942-1993, México, El Colegio de México, 2010. 
su operación política. Es, a no dudarlo, una de las élites locales más experimentadas del priismo, con que era previsible que alimentara su equipo de trabajo; sin embargo, Peña Nieto ha recurrido a otras reservas estatales. Antes de analizar las características de la élite que acompaña al mandatario, conviene detenerse brevemente en las que fueron distintivas del priismo tradicional, determinado por el dominio de la política nacional y, por supuesto, de su permanencia.

\section{LA ÉLITE PRIISTA TRADICIONAL}

La época moderna de la política mexicana se sitúa, convencionalmente, a partir de 1946 con el gobierno de Miguel Alemán, cuando se iniciaron las administraciones integradas por civiles, incluido el propio jefe del ejecutivo. Su presidencia será la primera en establecer un perfil de los secretarios de Estado que, sin variaciones sustantivas, será observado hasta la derrota del PRI en el año 2000. Como se observa en el cuadro 5, los miembros de los gabinetes priistas tuvieron como característica básica la de haberse formado principalmente en la administración pública federal y no, como tradicionalmente se ha supuesto, en los puestos de elección ni menos aún partidarios. Mientras el $60 \%$ de los secretarios desarrolló toda su carrera en el gobierno federal, no hubo nadie que lo hiciera únicamente en las otras áreas formativas. Cuando aparecen los puestos de elección y partidarios, siempre es en combinación con los administrativos, nunca por separado y de forma determinante. Eso indica que los políticos que gobernaron la mayor parte del siglo pasado y que fueron reconocidos como políticos tradicionales se formaron en la administración pública. Un elemento que no debe perderse de vista es que esta pauta de formación se mantiene constante, independientemente del sexenio en particular, e incluso en algunos aumenta notablemente.

Si estas trayectorias muestran una diferencia con otros sistemas políticos, en los cuales los partidos y, sobre todo, las carreras electorales predominan como matrices formativas de los funcionarios, en el caso mexicano no es tan sorprendente si se tiene presente 
que desde la década de 1940 el gobierno federal concentró no sólo la formación y puesta en práctica de las políticas públicas, sino la administración de los recursos financieros y la política misma. En esas circunstancias, la titularidad de una secretaría de Estado no significaba solamente administrar programas de desarrollo, sino negociación y control político.

\section{Cuadro 5}

Gabinetes presidenciales en los gobiernos del PRI, 1946-2000 Trayectorias de los funcionarios

\begin{tabular}{|c|c|c|c|c|}
\hline $\begin{array}{c}\text { Periodo } \\
\text { presidencial }\end{array}$ & $\begin{array}{c}\text { Solamente } \\
\text { administración }\end{array}$ & $\begin{array}{c}\text { Combinaciones } \\
\text { Admón.- } \\
\text { Elección-Partido }\end{array}$ & Otros & Total \\
\hline \multicolumn{5}{|c|}{ Miguel Alemán Valdés } \\
\hline $1946-1952$ & $11(50.0) *$ & 9 & 2 & 22 \\
\hline \multicolumn{5}{|c|}{ Adolfo Ruiz Cortines } \\
\hline $1952-1958$ & $10(58.8)$ & 7 & 0 & 17 \\
\hline \multicolumn{5}{|c|}{ Adolfo López Mateos } \\
\hline 1958-1964 & $9(52.9)$ & 8 & 0 & 17 \\
\hline \multicolumn{5}{|c|}{ Gustavo Díaz Ordaz } \\
\hline $1964-1970$ & $12(60.0)$ & 8 & 0 & 20 \\
\hline \multicolumn{5}{|c|}{ Luis Echeverría Álvarez } \\
\hline $1970-1976$ & $22(84.6)$ & 4 & 0 & 26 \\
\hline \multicolumn{5}{|l|}{ José López Portillo } \\
\hline 1976-1982 & $19(59.3)$ & 13 & 0 & 32 \\
\hline \multicolumn{5}{|c|}{ Miguel de la Madrid H. } \\
\hline 1982-1988 & $13(43.3)$ & 16 & 0 & 29 \\
\hline \multicolumn{5}{|c|}{ Carlos Salinas de Gortari } \\
\hline 1988-1994 & $27(61.4)$ & 17 & 0 & 44 \\
\hline \multicolumn{5}{|l|}{ Ernesto Zedillo } \\
\hline $1994-2000$ & $22(51.2)$ & 19 & 2 & 43 \\
\hline
\end{tabular}

Nota: se incluyen todos los cambios ocurridos durante cada administración.

* La cifra entre paréntesis es el porcentaje respecto de su propio total.

Fuente: investigación propia, diccionarios biográficos y prensa nacional. 
La segunda característica de esta élite es la larga duración de sus carreras profesionales, que al controlarla con la edad, revela que la política fue una actividad profesional de dedicación exclusiva. Como se observa en el cuadro 6, el promedio de años de carrera para los secretarios en todo el periodo priista es de 21.8 años de servicio ininterrumpido, lo que significa que colaboraron consecutivamente en poco más de tres sexenios. Si se tiene presente que el promedio de edad al momento de hacerse cargo de la secretaría es de 48.8 años, resulta que los políticos habían destinado a sus carreras casi la mitad de sus vidas. Por último, la gran mayoría de los secretarios desarrolló sus trayectorias en puestos jerárquicos sucesivos y en dependencias de una misma área de actividad. Con estos antecedentes es entendible que al ser nombrado secretario de Estado el funcionario contara con experiencia y el conocimiento especializado en la actividad propia de la dependencia. ${ }^{17}$

La tercera característica de esta élite es la amistad o, al menos, cercanía personal de los presidentes con los miembros de sus gabinetes. Si todos los presidentes, como fue tradicional hasta 1994, surgían del gabinete presidencial y designaban como secretarios a funcionarios con carreras similares a las suyas, resulta obvio que tuvieron trayectorias iguales y que durante su desarrollo pudieron no sólo conocer sus especialidades sino construir amistades que, por definición, suponen identidad de intereses y confianza recíproca.

Estas características construyeron un perfil del político-funcionario priista que dio como resultado una élite muy homogénea que, sin embargo, sólo pertenecía al partido de manera formal, toda vez que su verdadera carrera y, en particular, su ascenso político, dependían de su permanencia en la administración pública. Por supuesto que esa permanencia, como resultó claro a partir de 2000, dependía de que el PRI ganara las elecciones. La relación de la élite con el partido era absolutamente funcional y no suponía desarrollar una activa militancia partidaria que, entre otros resultados, los llevara a competir por cargos de elección. Esta característica básica de la élite

${ }^{17}$ Desde luego que éstas son características generales de un amplio conjunto de funcionarios, lo que no significa que no haya más de una excepción en la preparación y conocimiento. 
llegaría a su crisis durante los años noventa, cuando la llamada tecnocracia dominaba plenamente la política y había logrado desplazar a los políticos tradicionales. Fue entonces cuando varios líderes y grupos priistas, encabezados por algunos gobernadores, obligaron a un cambio estatutario que impuso como condición para ser candidato a un puesto de elección y, en especial para la Presidencia, contar con cargos en el partido y al menos un puesto de elección previo. ${ }^{18}$

Cuadro 6

Gabinetes presidenciales en los gobiernos del PRI, 1946-2000 Edad y años de carrera política de los funcionarios

\begin{tabular}{lcc}
\hline Periodo presidencial & $E d a d^{\mathrm{a}}$ & Total de años de carrera $^{\mathrm{b}}$ \\
\hline $\begin{array}{l}\text { Miguel Alemán Valdés } \\
\text { 1946-1952 }\end{array}$ & 44.6 & 16.6 \\
$\begin{array}{l}\text { Adolfo Ruiz Cortines } \\
\text { 1952-1958 }\end{array}$ & 50.0 & 20.8 \\
$\begin{array}{l}\text { Adolfo López Mateos } \\
\text { 1958-1964 }\end{array}$ & 51.7 & 26.3 \\
$\begin{array}{l}\text { Gustavo Díaz Ordaz } \\
\begin{array}{l}\text { 1964-1970 } \\
\text { Luis Echeverría Álvarez }\end{array}\end{array}$ & 50.8 & 27.3 \\
$\begin{array}{l}\text { 1970-1976 } \\
\text { José López Portillo }\end{array}$ & 49.8 & 20.4 \\
$\begin{array}{l}\text { 1976-1982 } \\
\text { Miguel de la Madrid H. }\end{array}$ & 49.1 & 21.9 \\
$\begin{array}{l}\text { 1982-1988 } \\
\text { Carlos Salinas de Gortari }\end{array}$ & 49.0 & 24.0 \\
$\begin{array}{l}\text { 1988-1994 } \\
\text { Ernesto Zedillo }\end{array}$ & 51.2 & 19.5 \\
$\begin{array}{l}\text { 1994-2000 } \\
\quad\end{array}$ & 43.1 & 19.8 \\
\hline
\end{tabular}

a Es la edad al momento de ser designado secretario de Estado.

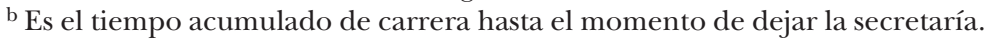
Fuente: Investigación propia, diccionarios biográficos y prensa nacional.

${ }^{18}$ En la última asamblea nacional del PRI, efectuada en marzo de 2013, fue retirada esa condición. 
Conviene no perder de vista que este esquema de ascenso y preparación no fue planeado ni menos aún sistematizado en ningún momento. Fue altamente eficaz, pero dependió de un factor por completo externo a la propia élite como era el mantener el predominio electoral del PRI. Si algo podría alterar por completo este sistema era la alternancia, pues si otro partido ocupara la Presidencia atraería a políticos propios, con carreras y funciones alejadas de la administración pública, y desmontaría la base generacional de ascenso que el priismo había implantado en la administración pública. Esta circunstancia tendría consecuencias nacionales porque llevaría al poder a élites sin experiencia administrativa, pero para el PRI significaba la ruptura de una tradición de reemplazo generacional que igualmente tendría repercusiones en la experiencia administrativa y política de sus militantes. Al ocurrir la eventualidad de que el PRI recuperara el poder, el mandatario no podría reproducir el viejo patrón de reclutamiento y ascenso del que dispusieron sus antecesores.

Si Peña Nieto solamente cuenta con experiencia local, sería esperable que su equipo de gobierno estuviera integrado por conocidos suyos, con carreras similares o, peor aún, con subordinados, pero formados en la misma entidad. También, como consecuencia, sería esperable que la relación entre ellos fuese directa, basada prioritariamente en la amistad y los compromisos personales. Las expectativas, sin embargo, no se han cumplido en este primer equipo de gobierno porque Peña Nieto ha designado a funcionarios que no han tenido necesariamente contacto directo con él, algunos con edad y carreras similares a la suya pero desarrolladas en otros estados, y otros, notoriamente mayores a él, con trayectorias por completo independientes a la suya, lo que impidió los contactos directos.

El primer indicador que puede situar las carreras y orígenes del equipo de Peña Nieto es su edad. El nuevo presidente tiene 47 años (cuadro 7), pero su gabinete tiene un promedio de 56 . Solamente tres funcionarios tienen edades inferiores a la suya y el resto se sitúa en el amplio rango de 50 a más de 60 años de edad. Este dato ilustra bien que la generación que acompaña al presidente se desarrolló al menos una década antes de que él comenzara la suya en el Estado de México, lo que no facilitó la cercanía personal. 


\section{Cuadro 7}

Gabinete del presidente Enrique Peña Nieto

Edad y años de carrera política

\begin{tabular}{lcc}
\hline Nombre & Edad $^{\text {a }}$ & Total de $_{\text {anos de } \text { carrera }^{\text {b }}}$ \\
\hline Enrique Peña Nieto & 47 & 17 \\
Emilio Chuayffet & 62 & 28 \\
Pedro Joaquín Coldwell & 63 & 38 \\
Ildefonso Guajardo & 56 & 12 \\
Juan José Guerra Abud & 61 & 10 \\
Mercedes Juan López & 70 & 22 \\
Enrique Martínez y Martínez & 65 & 31 \\
José Antonio Meade & 44 & 15 \\
Jesús Murillo Karam & 65 & 29 \\
Alfonso Navarrete Prida & 50 & 18 \\
Miguel Angel Osorio Chong & 49 & 18 \\
José Carlos Ramírez Marín & 52 & 19 \\
Rosario Robles & 57 & 7 \\
Gerardo Ruiz Esparza & 64 & 36 \\
Claudia Ruiz Massieu & 41 & 7 \\
Luis Videgaray Caso & 45 & 11 \\
\hline
\end{tabular}

${ }^{\text {a }}$ Es la edad al momento de ser designado secretario de Estado.

${ }^{\mathrm{b}}$ Es el tiempo acumulado al momento de ser designado.

Nota: El gabinete de Peña Nieto es el designado en diciembre de 2012 y que se mantenía sin cambios en febrero de 2014.

Fuente: Investigación propia. Prensa diaria, información oficial.

Los años de carrera fortalecen esta circunstancia. Como es de esperar, hay una tendencia muy clara a que el tiempo de carrera sea mayor conforme aumenta la edad de la persona, lo que lleva a la formación de dos grupos de funcionarios: los jóvenes, como Peña Nieto, con carreras entre 7 y 20 años, y los mayores, que rebasan los 50 años de edad, con trayectorias que rondan los 30 de actividad política. En el primer caso se encuentra la mayoría de secretarios (10), muchos en cargos relevantes, como las secretarías de Gobernación y Hacienda, y solamente 5 en el segundo grupo. Si este dato sugiere que, al final, el grueso de funcionarios es cercano al presidente, al revisar otros indicadores, como tipos de carrera y, 
sobre todo, lugares donde se desarrollaron, la conclusión es por completo distinta.

Contra las previsiones que se habían tenido, la mayoría de funcionarios no procede del Estado de México, sino que se formó en otras entidades de la República y la política federal. Como se desprende del cuadro 8 , solamente 5 secretarios nacieron o desarrollaron sus carreras en el mismo estado de origen del presidente y en los cinco las carreras son más amplias, pues a diferencia del presidente no se restringen al ámbito local. Más aún, 9 de los 15 secretarios tienen trayectorias en las que los puestos federales se combinaron con los locales, en entidades muy alejadas de la del mandatario. De nuevo, todos los indicadores conducen a la conclusión de que se trata, con muy pocas excepciones que se verán enseguida, de funcionarios con carreras paralelas a la presidencial, sin relaciones directas ni menos aún de subordinación. Antes de explorar las posibles relaciones, es necesario revisar el tipo de carreras de los secretarios.

La identificación local-federal puede resultar engañosa, porque únicamente sitúa el espacio geográfico del individuo pero no indica nada del tipo de tareas desarrolladas. El cuadro 9 proporciona esta información. Como se ve, el cambio en el patrón formativo del priismo previo a la alternancia es radical: el carril administrativo que fue determinante en el pasado se reduce ahora al mínimo (2 de 15 funcionarios, igual a 14\%), mientras que los ámbitos electoral y partidario cobran una inusual preponderancia (12 funcionarios, equivalente a $86 \%$ del total). Aun así, es revelador que la carrera administrativa no desaparezca de las trayectorias, pues está evidentemente presente en todos los secretarios. Este dato es importante porque si el PRI estuvo fuera del poder durante doce años, la administración pública federal no pudo ser el ámbito formativo; y si se tiene presente que procede de entidades de la República, su experiencia administrativa solamente pudo obtenerse en los gobiernos locales.

Ahora sí puede trazarse el perfil de los secretarios: la mayoría realizó sus carreras en varios estados, en tareas administrativas, en puestos de elección y de su partido y, por ende, con nulos contactos profesionales entre sí. Sin el control y la presencia en 
las instituciones federales, el priismo se retiró a los estados y, como era usual, en ellos ocupó los cargos políticos que estuvieron a su disposición: donde eran gobierno aparecen los puestos administrativos, además de los electorales y partidarios, pero donde fue desplazado y constituía la oposición política, se desarrollaron en la competencia electoral y en la carrera partidaria.

\section{Cuadro 8}

Gabinete del presidente Enrique Peña Nieto Tipo de carrera política

\begin{tabular}{|c|c|c|c|}
\hline \multirow[b]{2}{*}{ Nombre } & \multicolumn{2}{|c|}{ Lugar de } & \multirow[b]{2}{*}{ Tipo: } \\
\hline & Nacimiento & Carrera & \\
\hline Enrique Peña Nieto & Estado de México & Estado de México & $\mathrm{L}$ \\
\hline \multirow[t]{2}{*}{ Emilio Chuayffet } & Estado de México & Estado de México & \\
\hline & & Distrito Federal & L-F \\
\hline \multirow[t]{2}{*}{ Pedro Joaquín Coldwell } & Quintana Roo & Quintana Roo & \\
\hline & & Distrito Federal & $\mathrm{L}-\mathrm{F}$ \\
\hline \multirow[t]{2}{*}{ Ildefonso Guajardo } & Nuevo León & Nuevo León & \\
\hline & & Distrito Federal & L-F \\
\hline Juan José Guerra Abud & Estado de México & Estado de México & $\mathrm{L}$ \\
\hline Mercedes Juan López & Distrito Federal & Distrito Federal & $\mathrm{F}$ \\
\hline \multirow[t]{2}{*}{ Enrique Martínez y Martínez } & Coahuila & Coahuila & \\
\hline & & Distrito Federal & $\mathrm{L}-\mathrm{F}$ \\
\hline José Antonio Meade & Distrito Federal & Distrito Federal & $\mathrm{F}$ \\
\hline \multirow[t]{2}{*}{ Jesús Murillo Karam } & Hidalgo & Hidalgo & \\
\hline & & Distrito Federal & L-F \\
\hline \multirow[t]{2}{*}{ Alfonso Navarrete Prida } & Distrito Federal & Estado de México & \\
\hline & & Distrito Federal & L-F \\
\hline Miguel Angel Osorio Chong & Hidalgo & Hidalgo & $\mathrm{L}$ \\
\hline \multirow[t]{2}{*}{ José Carlos Ramírez Marín } & Yucatán & Yucatán & \\
\hline & & Distrito Federal & L-F \\
\hline Rosario Robles & Distrito Federal & Distrito Federal & $\mathrm{F}$ \\
\hline \multirow[t]{2}{*}{ Gerardo Ruiz Esparza } & Distrito Federal & Estado de México & \\
\hline & & Distrito Federal & L-F \\
\hline Claudia Ruiz Massieu & Distrito Federal & Distrito Federal & $\mathrm{F}$ \\
\hline \multirow[t]{2}{*}{ Luis Videgaray Caso } & Distrito Federal & Estado de México & \\
\hline & & Distrito Federal & $\mathrm{L}-\mathrm{F}$ \\
\hline
\end{tabular}

${ }^{a}$ L-local. F- federal.

Fuente: Investigación propia. Prensa diaria, información oficial. 


\section{Cuadro 9}

Gabinete del presidente Enrique Peña Nieto

Trayectorias de los funcionarios

\begin{tabular}{lll}
\hline \multicolumn{1}{c}{ Nombre } & \multicolumn{1}{c}{ Secretaría } & Tipo de Carrera $^{\text {a }}$ \\
\hline Enrique Peña Nieto & - & A-E \\
Emilio Chuayffet & Educación Pública & A-E-P \\
Pedro Joaquín Coldwell & Energía & A-E-P \\
Ildefonso Guajardo & Economía & A-E-P \\
Juan José Guerra Abud ${ }^{b}$ & Medio Ambiente & A-E \\
Mercedes Juan López & Salud & A-E \\
Enrique Martínez y Martínez & Agricultura & A-E-P \\
José Antonio Meade & Relaciones Exteriores & A \\
Jesús Murillo Karam & Procuraduría General de la & \\
& República & A-E-P \\
Alfonso Navarrete Prida & Trabajo y Previsión Social & A-E \\
Miguel Angel Osorio Chong & Gobernación & A-E \\
José Carlos Ramírez Marín & Reforma Agraria & A-E-P \\
Rosario Robles & Desarrollo Social & A-E-P \\
Gerardo Ruiz Esparza & Comunicaciones y Transportes & A \\
Claudia Ruiz Massieu & Turismo & A-E \\
Luis Videgaray Caso & Hacienda y Crédito Público & A-E-P \\
\hline
\end{tabular}

a A- administrativa E- electoral P- partidaria.

${ }^{\mathrm{b}}$ Guerra Abud recientemente se afilió al Partido Verde pero pertenecía al PRI al inicio de su carrera.

c Robles no pertenece al PRI. Todos los cargos considerados en su carrera fueron como militante del PRD, del cual incluso fue presidenta nacional. Renunció al PRD en 2004.

Fuente: Investigación propia. Prensa nacional, información oficial.

No es, sin embargo, tan aleatoria la selección de secretarios. Puede encontrarse tanto un criterio de lealtad por conocimiento directo, como de confianza en tareas políticas y económicas. El primero es fácil encontrarlo en cinco funcionarios: Juan José Guerra Abud, Miguel Ángel Osorio, Alfonso Navarrete, Gerardo Ruiz Esparza y Luis Videgaray. El primero es un viejo conocido del presidente, porque fue secretario de Desarrollo Económico entre 1993 y 1999, y durante la gubernatura de Emilo Chuayffet en el Estado de México y Peña Nieto se desempeñó como su secretario particular. 
En rigor, ese fue el primer cargo que tuvo el actual presidente cuando contaba con 27 años de edad. Después de esa responsabilidad, Guerra Abud abandonó la política para dedicarse a actividades privadas, hasta 2009, cuando fue diputado federal postulado por el Partido Verde.

A Osorio Chong lo une la identificación política y el reconocimiento de su experiencia. Osorio fue gobernador del estado de Hidalgo, una entidad que no sólo comparte cercanía geográfica con el Estado de México sino también la existencia de una élite política bien preparada que tampoco ha perdido la gubernatura pese a tener una intensa competencia partidaria que ha dado lugar a la alternancia en el congreso y los municipios. ${ }^{19}$ Osorio fue gobernador en el mismo periodo en que Peña Nieto lo fue en el Estado de México, lo que propició una fuerte relación personal e institucional. No es para nada sorprendente que Osorio esté al mando de la Secretaría de Gobernación y que haya emprendido una reestructuración institucional que busca fortalecer su intervención política.

Navarrete, Ruiz Esparza y Videgaray, aun cuando nacieron en el Distrito Federal, han desarrollado buena parte de sus carreras en el Estado de México y durante el gobierno de Peña Nieto fueron miembros de su gabinete. Navarrete fue secretario de Desarrollo Metropolitano y Ruiz Esparza de Comercio. Videgaray fue secretario de Finanzas, presidente estatal del PRI, coordinador de campaña del gobernador sucesor Eruviel Ávila y diputado federal. Dichos cargos que han abonado su reconocida habilidad tanto en los asuntos financieros como en los políticos, lo que confirmaría en 2011 como coordinador de la campaña presidencial de Peña Nieto.

Como titulares de Educación Pública, Energía y la Procuraduría General de la República, Peña Nieto ha designado a tres políticos reconocidos por su larga trayectoria pero con los cuales no comparte ningún contacto en su corta y local carrera. Emilio Chuayffet,

${ }^{19}$ La élite hidalguense también ha originado interpretaciones simplistas sobre la supuesta existencia de un grupo único que, sin embargo, no sostiene la evidencia empírica. Véase el interesante estudio de Matthew Richards, "The Elite of Hidalgo State, Mexico: The Grupo Huichapan, 1937-2005", tesis doctoral, Swansea, University of Wales, mayo de 2006. 
Pedro Joaquín Coldwell y Jesús Murillo Karam tienen en común una sólida experiencia política, muy anterior a la del presidente. Los tres no sólo han sido gobernadores de sus estados (de México, Quintana Roo e Hidalgo), sino que también se han desempeñado como secretarios o subsecretarios de Estado en anteriores sexenios priistas, además de numerosos cargos de elección y de partido. Sus designaciones sugieren que Peña Nieto desea aprovechar esa experiencia, no necesariamente porque tengan el conocimiento especializado en las áreas que se les ha confiado (educación, energía y seguridad), sino porque son áreas conflictivas que pueden afectar el desempeño del gobierno y que demandan probada experiencia política. Los tres están destinados a desarrollar reformas centrales que provocarán tensiones: la educativa, que se inició en enero de 2013 y que ha concitado respuestas violentas de algunos sectores magisteriales; la de energía y petróleo, que involucra a PEMEx y la CFE, discutida desde 2013 y aprobada en 2014, que además de provocar fricciones con el sindicato respectivo ha implicado intensas negociaciones con los partidos políticos, toda vez que se ha reformado el principal símbolo nacionalista del país, y la revisión tanto de la procuración de la justicia como del esquema de seguridad interna heredada del gobierno de Felipe Calderón contra el narcotráfico. Coldwell, además, tiene como antecedente inmediato que fue presidente del PRI, bajo cuya dirección se postuló Peña Nieto y se desarrolló su campaña presidencial.

En el caso de Chuayffet, también está presente el origen geográfico que, no obstante, se ha magnificado. Se ha supuesto que su nombramiento se debe a que en su gobierno en el Estado de México Peña Nieto fue su subordinado. La idea, aunque atractiva, no se sostiene con los datos disponibles, pues Chuayffet fue gobernador de 1993 a 1995, año en que partió a la ciudad de México para ocupar la Secretaría de Gobernación. Desde 1993 Guerra Abud fue designado secretario de Desarrollo Económico en la entidad e incorporó a Peña Nieto como su secretario particular, un cargo menor en la estructura gubernamental y con pocas posibilidades de relacionarse con el mandatario estatal. El contacto se reduciría aún más porque Chuayffet estaría involucrado activamente en la política nacional que, a la postre, lo llevaría a renunciar en 1998. No regresó 
a la política, ni local ni nacional, hasta 2003 como diputado federal para enfrentar nada menos que a Elba Esther Gordillo, eterna dirigente del sindicato magisterial, en ese entonces también secretaria general del PRI, líder de su bancada y aliada del presidente panista Fox. Chuayffet se convertiría en el brazo político de Roberto Madrazo, presidente del partido, contra la dirigente, y tras la renuncia de Gordillo, fue líder de la diputación priista. Más que cercanía entre Peña Nieto y Chuayffet, el presidente parece haber aquilatado ese enfrentamiento porque Chuayffet volvió a enfrentar a la lideresa magisterial en 2003 al iniciarse la reforma educativa. Gordillo, que había construido un indiscutible poder en el sindicato de maestros, desde el cual había financiado la fundación de un nuevo partido (Nueva Alianza, que sería determinante en la victoria de Calderón en 2006, cuando venció a López Obrador por menos de un punto porcentual), y que tras su salida del PRI se había comprometido con Fox y Calderón, fue encarcelada por malversación de fondos en una operación política y jurídica coordinada por Osorio, Murillo y Chuayffet.

El pragmatismo presidencial puede confirmarse con otras designaciones. La más destacada es la del nuevo canciller José Antonio Meade, sin ninguna experiencia internacional ni menos diplomática y que tampoco cuenta con ningún antecedente priista. Aunque Meade es abogado por la UNAM, es especialista en economía y finanzas públicas por el IтAм y la Universidad de Yale, y desde fines de los años noventa (es decir, desde la última administración priista y durante las dos panistas) ha trabajado en destacados puestos financieros del sector público, incluida la titularidad de la Secretaría de Hacienda.

Meade es un claro ejemplo de la ascendencia que desde los años ochenta ha tenido la tecnocracia financiera, formada durante los últimos tres gobiernos priistas (De la Madrid, Salinas y Zedillo), pero que no tiene ningún compromiso político con el PRI pero tampoco con el Pan. Esa tecnocracia no sólo dominó aquellos tres sexenios, incluso al controlar la Presidencia misma, sino que dirigió las finanzas públicas durante las administraciones de Fox y Calderón. ${ }^{20}$

${ }^{20}$ La única posible excepción fueron los años de 2009 a 2011, cuando el titu- 
Es un grupo con un alto ethos burocrático y especializado que no se reconoce como parte de un partido ni con vocación política, con amplio reconocimiento internacional, ${ }^{21}$ lo que le ha permitido estar al frente de la economía mexicana desde fines de los años ochenta, cuando se puso en marcha el modelo financiero y continuar durante el panismo, una vez conseguida la alternancia.

Meade no solamente llega como destacado representante de la tecnocracia, sino como responsable de imprimir a las relaciones internacionales un cambio radical hacia el comercio, que fortalezca la vinculación de la economía mexicana con la internacional. $\mathrm{Si}$, además, se tiene presente que Luis Videgaray ${ }^{22}$ también forma parte de esta tecnocracia y que se encuentra al frente de Hacienda, la profundización del proyecto económico está garantizada. ${ }^{23}$ Peña Nieto ha continuado esta fuerte vinculación con la tecnocracia e incluso la ha extendido a un ámbito totalmente diferente, como es la diplomacia.

Con los restantes secretarios las motivaciones son variadas. En algunos también predomina la experiencia y el conocimiento especializado (Enrique Martínez y Martínez en Agricultura y Mercedes Juan López en Salud), o de nuevo el pragmatismo político, como es el caso de Rosario Robles, militante de izquierda, que fuera tan reconocida en su momento que incluso llegó a dirigir

lar de Hacienda fue el panista Ernesto Cordero, pero aun así los subsecretarios, entre los cuales se encontraba Meade, fueron los verdaderos responsables de la secretaría.

${ }^{21}$ Varios de sus representantes ocupan cargos relevantes en organismos internacionales, como José Ángel Gurría, Secretario General de la ocDE; Alejandro Werner, director del Departamento del Hemisferio Occidental del FMI y Herminio Blanco, que quedara como uno de los dos candidatos finalistas a dirigir la omc en 2013.

${ }^{22}$ Videgaray ha roto con esa tradicional neutralidad partidaria de la tecnocracia, al comprometerse con el PRI públicamente en los últimos años.

${ }^{23}$ Por si hubiera alguna duda de esta garantía, habría que agregar que Agustín Carstens, actual gobernador del Banco de México, es otro de los más reconocidos tecnócratas. Con larga carrera en el banco que ahora preside, y en Hacienda, cuya titularidad desempeñó al principio del gobierno de Calderón, también llegó a ser Director Ejecutivo del FMI. Meade fue coordinador de asesores del secretario de Hacienda Carstens y poco después su subsecretario de Ingresos. 
el PRD, pero al que se vería obligada a renunciar en medio de un escándalo personal y de violentos ataques de sus excompañeros. Robles, cuando la campaña presidencial entró en su fase final y la candidatura de Andrés Manuel López Obrador se había convertido ya en la principal adversaria de Peña Nieto, ofreció su apoyo públicamente al candidato priista. Designarla como secretaria de Desarrollo Social, la dependencia encargada de los programas sociales, con clara influencia electoral, es un reconocimiento de la que una vez fuera jefa de Gobierno del Distrito Federal, donde el PRD ha sostenido su prolongado dominio en los programas asistenciales. Además de aprovechar su experiencia, Robles se ha convertido en un ariete contra el PRD capitalino, el más fuerte y consolidado en todo el país. Y, por si fuera poco, con su nombramiento Peña Nieto muestra su disposición al pluralismo político.

\section{ÉLITE PRIISTA RENOVADA}

El triunfo de Enrique Peña Nieto es un triunfo también del partido, y las primeras designaciones revelan que no tiene dudas de gobernar con priistas. Pero hay cambios significativos, marcados tanto por las circunstancias políticas como por la generación a la que pertenece el presidente. A diferencia de las prácticas del pasado, el nuevo mandatario no se ha rodeado de un grupo de colaboradores cerrado, en el que predominen las relaciones personales. Se ha rodeado de priistas tradicionales, con lo cual no sólo recupera su experiencia sino que envía un mensaje de conciliación intergeneracional. Pero también ha incorporado a políticos jóvenes que, como él, han desarrollado sus carreras en los estados, y a otros en los que confía debido a que han compartido carreras políticas. El primer gabinete de Peña Nieto refleja la nueva realidad política del país, de la cual él mismo es resultado; también evidencia que el PRI, ese viejo partido en apariencia destinado a desaparecer con la alternancia, ha sabido actualizarse y, lo más importante, preparar nuevas generaciones de políticos. No hay duda de que la nueva conformación de poder ya no es central como en el pasado, y a Peña Nieto, que lo vivió como mandatario, 
no puede pasarle inadvertido la influencia que han acumulado los gobernadores, que incluye no sólo recursos económicos sino también el control de las élites locales. Pero aun así Peña Nieto no ha construido un gabinete de representación estatal, pues muchas entidades y, por ende, muchos grupos locales no figuran en el plano nacional. Es el caso, por ejemplo de grupos tan fuertes como el de Veracruz o el de Tamaulipas, que no aparecen en ningún puesto federal importante. El reconocimiento de esa realidad no se ha convertido en un reparto grupal. Lo relevante es que Peña Nieto puede mantener la autoridad suficiente en medio de poderes tan fragmentados como los que han resultado de la transición.

Otro aspecto a destacar es que pese a todos los cambios, algunas tradiciones se mantienen, como son los patrones formativos priistas. Las carreras de la nueva élite revelan que los carriles administrativo, electoral y partidario siguen siendo las fuentes de preparación y adiestramiento, si bien el ámbito geográfico ha cambiado. Debido a la derrota presidencial, pero sobre todo a la profunda descentralización del poder, la política ha involucrado activamente a las élites locales. Nuevos líderes y grupos, con asiento estatal, han aparecido y, lo más importante, han tenido influencia decisiva en la política nacional.

La semblanza de esta élite no puede, en forma alguna, considerarse como una nueva pauta para el futuro priista. Sería exagerado suponer que se mantendrán durante toda la administración y que, en caso de renovarse, será relevada con los mismos criterios. Este examen, sin embargo, ha sido útil para observar cómo el priismo ha sido capaz de sobrevivir a la alternancia, aprender a competir y a ganar en los términos que la misma democracia impone. Pero sí ha podido adaptarse a las nuevas condiciones políticas, también ha logrado renovar a sus élites ahí donde se ha trasladado la política, a los estados del país.

\section{Bibliografía}

Aspe, Pedro, El camino mexicano de la transformación económica, México, FCE, 1993. 
Aziz, Alberto, "La construcción de la democracia electoral", en Ilán Bizberg et al. (comps.), Una historia contemporánea de México, t. 1, México, Océano, 2003.

Becerra, Pedro et al., La mecánica del cambio político en México: elecciones, partidos y reformas, México, Cal y Arena, 2000.

Dornbusch, Rudiger y Sebastian Edwards, The Macroeconomics of Populism in Latin America, Chicago, University of Chicago Press, 1991.

Hernández Rodríguez, Rogelio, Amistades, compromisos y lealtades. Lideres y grupos políticos en el Estado de México, 1942-1993, México, El Colegio de México, 2010.

- - El centro dividido. La nueva autonomía de los gobernadores, México, El Colegio de México, 2008.

— , "Una competencia sin reglas: la candidatura de presidencial de Roberto Madrazo", Política y gobierno, CIDE, 2009.

Huntington, Samuel P., "Social and Institutional Dynamics of One-Party Systems", en Samuel P. Huntington y Clement H. Moore, Authoritarian Politics in Modern Society The Dynamics of Established One-Party Systems, Nueva York, Basic Books, Inc. Publisher, 1970.

Linz, Juan J., “An Authoritarian Regime: Spain”, en Eric Allardt y Stein Rokkan (eds.), Mass Politics, Nueva York, The Free Press, 1970.

Merino, Mauricio, La transición votada, México, FCE, 2003.

Oxhorn, Philipe y Pamela K. Starr (eds.), Markets and Democracy in Latin America, Boulder, Lynne Rienner Publishers, 1999.

Pacheco, Guadalupe, “¿Hacia la cuarta etapa del partido de la Revolución? La elección interna de dirigentes del PRI en febrero de 2002”, Foro Internacional, núm. 184, abril-junio de 2006.

, "La redefinición de las reglas internas de poder en el PRI, 19882001. De la XIV a la XVIII Asamblea Nacional”, Argumentos, núm. 43, diciembre de 2002.

Richards, Matthew, "The Elite of Hidalgo State, Mexico: The grupo Huichapan, 1937-2005", tesis doctoral, Swansea, University of Wales, mayo de 2006.

Rodríguez, Victoria, La descentralización en México, México, FCE, 1999. y Peter M Ward, New Federalism and State Government in Mexico: Bringing the States Back-In, US-Mexico Policy Studies Monograph Series, núm. 10, LBJ School of Public Affairs, The University of Texas at Austin, 1999. 
Rousseau, Isabelle, México: ¿¿una revolución silenciosa? Elites gubernamentales y proyecto de modernización (1970-1995), México, El Colegio de México, 2000.

Ward, Peter M. y Victoria E. Rodríguez, "New Federalism, Intra-governmental Relations and Co-governance in Mexico", Journal of Latin American Studies, núm. 3, octubre de 1999. 